\title{
Compromisso ético no trabalho da enfermagem no cenário da internação hospitalar
}

\author{
Danae Beatriz Barbosa Cecere ${ }^{1}$ \\ Rosemary Silva da Silveira ${ }^{2}$ \\ Cibeli da Rosa Duarte ${ }^{3}$ \\ Geani Farias Machado Fernandes ${ }^{4}$
}

Tem-se como objetivo conhecer a visão dos trabalhadores sobre o compromisso no exercício das ações de enfermagem em uma unidade hospitalar. Utilizou-se como proposta metodológica a pesquisa qualitativa através das técnicas de observação e entrevista. A análise temática permitiu compreender a visão dos trabalhadores da enfermagem acerca de seu comprometimento na instituição e o objeto de suas ações, identificando fatores que influenciam na qualidade do cuidado, como a sobrecarga de trabalho e a própria frustração com a qualidade do produto de seu trabalho, podendo desmotivar e gerar a falta de comprometimento dos profissionais.

Descritores: Ética, Ética em Enfermagem, Trabalhadores.

\section{Ethical commitment in nursing work at hospitalization scenery}

The aim of this paper is to know the nursing staff's point of view on the commitment concerning the nursing actions at a hospital unity. It was used the qualitative research as methodological proposal by means of observation techniques and interview. The theme analysis allowed us to comprehend the nursing staff's point of view on their commitment to the institution as well as the consequences of their actions by identifying factors that influence on quality of care like work overload and the frustration concerning the results of their work, what can desmotivate and generate de lack of commitment by the professionals.

Descriptors: Ethics, Nursing Ethics, Nursing Staff.

\section{Compromiso ético en el trabajo de enfermería en el escenario de hospitalización}

Se trata de una investigación con el objetivo de conocer la visión de los trabajadores sobre el compromiso en los ejercicios de las acciones de enfermería en una unidad hospitalar. Se utilizó como propuesta metodológica la investigación cualitativa a través de técnicas de observación y entrevista. La análisis temática permitió a nosotros conocer una visión de los trabajadores de enfermería a respecto de sus acciones, identificandose factores que influenciaron en la cualidad del cuidado como la sobrecarga de trabajo y la frustración con la cualidad del producto de su trabajo, que puede desmotivar y generar la falta del comprometimiento de los profesionales.

Descriptores: Ética, Ética em Enfermería, Trabajadores.

\section{INTRODUÇÃO}

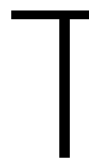

radicionalmente reconhecidos como profissionais do cuidado, os trabalhadores da enfermagem necessitam avaliar continuamente sua prática e, dessa forma, refletir como está ocorrendo o processo de cuidado, pois cuidar é muito mais do que um ato: "Envolve atenção prolongada às condições e necessidades dos clientes"(1:99). Cuidar "significa gostar de, ter um compromisso emocional e disposição para agir em benefício das pessoas com as quais se tem um relacionamento significativo"(2:106).

É possível que o fundamento da relação interpessoal entre trabalhadores da enfermagem e pacientes seja uma ação tanto de percepção e determinação da necessidade de cuidado quanto de emoção: um caso de reconhecimento do outro como ser humano(3).

Mediante as observações no cotidiano, vimos os diferentes graus de comprometimento dos trabalhadores da enfermagem no desempenho de seu fazer, envolvendo interesses pessoais, normatizações, conflitos de valores, do modo de agir, de comprometer-se e de pensar, refletindo nas relações estabelecidas com o outro e na realização dos

1 Enfermeira. Graduada pela Universidade Federal do Rio Grande - Furg. Enfermeira da Associação de Caridade Santa Casa do Rio Grande (RS). E-mail: danaececere@hotmail.com. 2 Enfermeira. Docente da Escola de Enfermagem e do programa de pós-graduação em enfermagem da Universidade Federal do Rio Grande - Furg. Doutora em enfermagem UFSC. Membro do Nepes e do Giate. E-mail: anacarol@mikrus.com.br.

3 Enfermeira do Hospital Universitário Doutor Miguel Riet Corrêa Jr. - Furg. Mestranda do programa de pós-graduação em enfermagem - Furg. Membro do Nepes. E-mail: cibelird@gmail.com.

4 Enfermeira. Docente da Escola de Enfermagem da Universidade Federal do Rio Grande - Furg. Doutora em enfermagem - UFSC. Membro do Nepes. E-mail: geani@vetorial.net. 
cuidados prestados aos pacientes, em que exigências e responsabilidades podem ser negligenciadas ${ }^{(4)}$.

A permissividade perante ações e condutas consideradas impróprias, a sensação de desconforto frente a algumas situações vivenciadas no contexto do trabalho da saúde e da enfermagem, em particular o desrespeito e a ausência de comprometimento com os direitos dos pacientes, bem como as ações de cuidado e as posturas diversificadas assumidas pelos trabalhadores da enfermagem, podem influenciar a ação de outros trabalhadores e comprometer a qualidade do cuidado aos pacientes. Essa aparente ausência de comprometimento ético no desenvolvimento do trabalho tem sido constatada em diversas pesquisas que estudam a temática ${ }^{(3-7)}$.

Tais percepções nos possibilitam questionar o motivo dessas diferenças de comprometimentos e posturas assumidas pelos trabalhadores no estabelecimento das relações com o outro e na prestação dos cuidados aos pacientes. Esse comprometimento depende da consciência de cada um? Da formação recebida? Do valor atribuído às ações de cuidado de enfermagem? Qual a postura dos trabalhadores da enfermagem frente às situações, exigências e responsabilidades no cuidado aos pacientes?

Pareceque os trabalhadores não percebem que, muitas vezes, tais posturas e a falta de comprometimento podem influenciar negativamente na qualidade do cuidado dos pacientes. Essa visão equivocada requer uma reflexão do trabalhador frente à percepção e à valorização dos espaços do sujeito nos processos assistenciais, além de tentar compreender o que move as pessoas no trabalho, mas também aquilo que as comove, ou seja, "os valores e sentimentos que dão a elas um senso de unidade e de identidade, em suas dimensões verdadeiramente humanas". Nesse sentido, o trabalho em saúde requer cooperação, ações coletivas, a criação de vínculos consigo mesmo, com os outros, com o contexto do trabalho, construindo-se e "reafirmando-se como sujeitos efetivos em sua ação"(8).

Entende-se que, para direcionar as ações e a continuidade do cuidado aos pacientes, é preciso que o trabalhador se envolva, se comprometa, participe das ações, o que requer respeito, estímulo e abertura de espaços para favorecer essa construção. Defende-se a ideia de que, para cuidar e atender com qualidade às necessidades dos pacientes, os trabalhadores precisam visualizá-los como o objeto e a finalidade de seu trabalho. Será que os trabalhadores da enfermagem estão preparados o suficiente para resgatar sua sensibilidade e comprometer-se com a finalidade de seu trabalho e para tornar-se presentes, estando conscientes dos valores que devem ser interiorizados no processo de cuidar, desempenhando uma postura ética?

Assim, pretende-se focalizar este estudo nos aspectos éticos, no que se refere à percepção dos trabalhadores da enfermagem em relação ao compromisso e responsabilidades a serem assumidos frente às ações de cuidados dispensadas aos pacientes. Objetiva-se conhecer a visão dos trabalhadores de enfermagem sobre seu compromisso na instituição hospitalar e em quem devem ser centradas suas ações.

\section{Metodologia}

Este estudo foi realizado a partir de uma abordagem qualitativa, numa tentativa de compreender e aprofundar os conhecimentos a partir da interação entre pesquisadoras e os sujeitos da pesquisa, identificando aspectos importantes de seu interesse a serem desvelados, ou seja, explorando os fenômenos em diversos contextos naturais ${ }^{(9)}$.

A pesquisa foi realizada em uma unidade de clínica médica de um hospital universitário do sul do Rio Grande do Sul, com nove trabalhadores da enfermagem (três enfermeiros, quatro técnicos de enfermagem e dois auxiliares de enfermagem). A coleta de dados ocorreu após a aprovação da pesquisa no Comitê de Ética em Pesquisa na Área da Saúde (Cepas), sob o parecer n 71/2008.

Os dados foram coletados no período de setembro a novembro de 2008, através das técnicas de observação e entrevista. $\mathrm{Na}$ observação dos sujeitos no ambiente de trabalho, as pesquisadoras estiveram atentas às ações dos trabalhadores, à disponibilidade e presteza no atendimento às solicitações dos pacientes e familiares e às prioridades estabelecidas em seu fazer, que foram registradas em um diário de campo. Utilizou-se um roteiro previamente elaborado para a realização das entrevistas,

gravadas e posteriormente transcritas.

A análise temática orientou a interpretação e o exame dos dados, que foram ordenados, classificados e estudados ${ }^{(10)}$. Após leitura flutuante dos achados, esses foram agrupados em categorias conforme sua similaridade e, finalmente, depois dos dados classificados, houve análise por meio do confronto com o referencial teórico.

\section{Resultados e discussões}

Este estudo possibilitou perceber, através das observações realizadas, que, em grande parte das situações, os trabalhadores não possuem critérios para determinar as ações e as decisões frente às necessidades de cuidado. Exemplo disso é que, ao serem solicitados por acompanhantes para a substituição de frascos de soroterapia, cuidados com higiene oral, corporal ou administração de analgesia, esses costumavam priorizar atividades em desenvolvimento, para posteriormente atender às solicitações.

Em média, foi observado que os trabalhadores levam de quatro a 30 minutos para atender à solicitação dos familiares ou pacientes. Esse tempo pode ser considerado pouco relevante para o trabalhador que se encontra envolvido com outras tarefas, mas significa uma "eternidade" para quem 
aguarda a resolução de um problema. Ao serem questionados sobre o modo de agir, os entrevistados - identificados por E1, E2, E3... - apontaram as seguintes causas:

"Eu acho que a rotina está pesada. A gente trabalha com um número reduzido de funcionários, com uma quantidade muito grande de pacientes, com pacientes bastante dependentes". E4

Das causas apontadas pelos trabalhadores, a sobrecarga foi a que surgiu mais fortemente, sendo que, no turno da noite, os funcionários assumiam até 12 pacientes, número que era reduzido quase à metade durante o dia - em torno de sete pacientes para cada trabalhador. Por se tratar de um hospital universitário, onde a equipe é maior do que em outros hospitais, seria esse número de pacientes realmente excessivo? Outro fator que pode estar influenciando os modos de agir desses trabalhadores se relaciona ao fato de um número significativo de trabalhadores temporários comporem parte da equipe de enfermagem, dificultando, dessa forma, o estabelecimento de vínculo com a instituição e o necessário comprometimento com sua missão.

Buscar conhecer a visão dos trabalhadores da enfermagem sobre seu compromisso implicou propiciar momentos de reflexão sobre os diferentes modos de ser e fazer a enfermagem. Nessa caminhada, foi imprescindível estar com eles, observando o desenvolvimento de suas ações e as possíveis repercussões, tanto para si quanto para os pacientes. No depoimento dos trabalhadores, foi destacada a importância atribuída à centralidade das ações de enfermagem, conforme expresso:

"As ações têm de ser centradas nos pacientes, que são o objetivo de nosso trabalho, nos procedimentos que a gente realiza, como na parte administrativa. Isso tudo fazemos pensando no paciente. É na escala de trabalho que fazemos, é a divisão diária dos funcionários, é a provisão do material, de equipamentos. Então tudo isso tem um objetivo comum, que é a assistência do paciente". E2

Colocar as ações de enfermagem no centro do processo de trabalho consiste em direcioná-las "a um sujeito específico, que tem uma abrangência maior enquanto social". Mais do que o domínio e a excelência da técnica, o fazer da enfermagem é, também, um "serviço à humanidade"(11:115).

Assim, os diferentes modos de ser e fazer a enfermagem devem ter "como foco central o fazer pelo bem-estar do outro, não como uma simples forma de cumprir com o compromisso profissional, mas pelo sentido dado à vida do ser humano"(11:117).

No entanto, mesmo reconhecendo que o objeto do trabalho da enfermagem é o cuidado ao paciente, os trabalhadores alegam que nem sempre conseguem centrar suas ações no atendimento das necessidades como desejariam ou deveriam, o que pode ser evidenciado na fala de E4:

"Infelizmente, em minha realidade de trabalho, nem sempre consigo centrar minhas ações no paciente, (...) desenvolver meu trabalho da forma que julgo correta, que seria colocar o paciente em primeiro lugar. Nem sempre tenho condições, por inúmeros fatores, de organizar o serviço, de diferenciar o cuidado. (...) Em alguns momentos, a burocracia acaba nos desviando de manter o paciente como o centro da atenção, como prioridade da atenção do cuidado da enfermagem".

Apesar da intenção e do aparente compromisso dos trabalhadores com a assistência, verificou-se que esses têm um entendimento de que nem sempre é possível efetuar o cuidado direto aos pacientes. Por outro lado, muitas das ações consideradas "burocráticas" são necessárias para a organização do trabalho da enfermagem. Esse afastamento do cuidado direto pode gerar sofrimento moral no trabalhador de enfermagem, que pode ocorrer quando há confronto entre o compromisso com o paciente e com a instituição, causando alguns sentimentos como sofrimento, frustrações e ansiedade ${ }^{(12)}$.

Nessa perspectiva, se o trabalhador deixa de cumprir seu fazer, pela sobrecarga de trabalho, por acomodação, por ausência de compromisso, por insatisfações e frustrações, é necessário fazer uma reflexão sobre sua prática e a busca de opções que possibilitem a interiorização de valores, a mudança de atitudes, para que não permaneçam "constantemente imersos no contexto de trabalho, desmotivados e acomodados"(3:152).

A fim de atingir e manter as ações necessárias para um efetivo cuidado,

é preciso que os membros da equipe de enfermagem trabalhem sinergicamente, ou seja, que compartilhem "o desenvolvimento de ideais e objetivos", pois a adoção de uma postura individualizada pode comprometer a qualidade do desempenho e influenciar o compromisso e a vida de cada trabalhador ${ }^{(13: 56)}$.

Sendo assim, o trabalho da enfermagem precisa ser desenvolvido coletivamente, pois sua finalidade requer o compromisso de cada um e de toda a equipe para cuidar satisfatoriamente dos pacientes. Acredita-se que, através de uma relação dialógica horizontal, na qual os sujeitos estejam abertos às contínuas reflexões sobre a prática, é possível superar as dificuldades e efetivar um processo de trabalho coletivo pautado no comprometimento ético ${ }^{(14)}$.

$\mathrm{Na}$ visão dos trabalhadores, parece haver uma ausência de compromisso por parte de alguns membros da equipe de enfermagem com o exercício de sua profissão, como colocado por E7 e complementado por E2, respectivamente:

"Às vezes, eu vejo um descaso dos funcionários (...): 'Ah! Tem curativo, mas o curativo está direitinho, não vamos mexer"';

"As pessoas estão cada vez menos compromissadas (...). As pessoas querem é fazer o básico para não comprometer seu nome na instituição e ponto final".

Para prover um trabalho com qualidade, o profissional de enfermagem deve realizar suas ações não só como quem presta um favor, mas sim como alguém que "cumpre um 
dever não apenas profissional, mas um comprometimento respeitoso com a vida e com os valores que se constroem ao longo da mesma"(11:114).

Esse comprometimento respeitoso com a vida precisa ser compreendido como a possibilidade de o trabalhador da enfermagem "assumir uma postura ética", o que denota aperfeiçoamento da capacidade de trabalhar com "as emoções conflitantes", uma força de caráter e um equilíbrio de vida, tornando-se um ser com habilidade para assegurar uma conduta ética em suas ações ${ }^{(15: 45)}$.

No entanto, muitas vezes, o reconhecimento do outro como um ser humano que necessita de cuidados pode ficar comprometido, e os trabalhadores da enfermagem deixam de exercer suas ações de cuidados, possivelmente porque julguem não serem necessárias, podendo "delegar" alguns cuidados para os acompanhantes. Muitos enfermeiros atribuem o que reconhecem como negligência à falta de tempo. Porém, disponibilizam tempo para atividades burocráticas, que poderiam ser facilmente delegadas a outros membros da equipe.

Durante as observações, ainda se pode perceber um aparente acordo entre os trabalhadores para que sejam priorizadas apenas a administração das medicações e a verificação dos sinais vitais dos pacientes mais graves, quando a equipe está desfalcada de funcionários.

Por outro lado, deve-se considerar que o fator pessoal pode influenciar no compromisso com o trabalho. Nesse sentido, a escolha profissional inadequada pode ser apontada como uma das causas que levam à ausência de compromisso por parte dos profissionais, provavelmente pela falta de identificação com o trabalho.

"Como em todo serviço, existem os bons, os que gostam muito da profissão e se esmeram muito no atendimento, e também os que não gostam muito, mas fazem por falta de opção." E5

De modo geral, os trabalhadores parecem estar descontentes com o resultado do próprio trabalho. Frente a esse descontentamento demonstrado durante as entrevistas, considera-se necessária a construção de medidas que minimizem as causas desse desconforto, tanto para melhorar a visão da própria equipe com seu trabalho quanto para prestar um atendimento de qualidade aos pacientes.

"Nosso compromisso seria mudar nossa realidade de trabalho (...). Hoje, a gente deveria, como categoria, como um conjunto, se unir e brigar para poder conseguir desenvolver um trabalho em que se consiga ter compromisso." $E 4$

Torna-se necessário que cada membro da equipe de enfermagem reflita acerca de seu compromisso com o trabalho, buscando avaliar o cuidado prestado direta e indiretamente ao paciente e planejando suas atividades de modo a garantir a qualidade da assistência de enfermagem.

Para isso, é preciso que a equipe exerça sua autonomia e atue de forma pró-ativa na reorganização do processo de trabalho. Assim, cada trabalhador deve individualmente se avaliar e exercer suas ações pautadas na ética e nos preceitos legais que a profissão exige.

Além disso, percebe-se como necessidade que a instituição desenvolva ações de educação permanente, que retomem conteúdos da ética no trabalho, direitos e deveres do trabalhador, assim como os direitos dos pacientes, e qualifiquem os servidores através do fortalecimento do desenvolvimento de competências e habilidades necessárias ao exercício da enfermagem.

Desse modo, para que a enfermagem possa desenvolver suas ações com compromisso e responsabilidade, é preciso buscar o desenvolvimento de um trabalho coletivo, criando condições favoráveis no ambiente de trabalho, através do diálogo, do envolvimento e da participação.

\section{Considerações finais}

Este estudo permitiu compreender a visão dos profissionais de enfermagem acerca de seu comprometimento na instituição e o objeto de suas ações, identificando alguns fatores que influenciam na qualidade do processo do cuidado.

Entre os problemas apontados pelos profissionais que interferem em seu ambiente de trabalho, destacamos a sobrecarga de trabalho e a própria frustração com a qualidade do produto de seu trabalho, que podem desmotivar e gerar a falta de compromisso dos profissionais.

Outro fator que merece destaque é a necessidade de estímulo por parte dos profissionais em relação a sua valorização, não apenas como força de trabalho, mas como pessoas, responsáveis por um fazer significativo. $\mathrm{O}$ retorno positivo das ações do profissional, além de proporcionar estímulo e valorização do indivíduo, pode influenciar em seu compromisso com o trabalho.

Pode-se perceber que o profissional se mostra comprometido com seu trabalho quando identifica que a qualidade da assistência prestada não é a que considera ideal e quando menciona a necessidade de buscar mudanças para a melhoria no ambiente de trabalho, tendo em vista que a carência de recursos materiais e humanos interfere no resultado.

Espera-se que esta pesquisa possa favorecer reflexões da enfermagem a respeito do compromisso com o objetivo de seu trabalho e que as questões levantadas possam servir de estímulo à busca de mudanças por parte da equipe, com a finalidade de qualificar seu fazer. Confia-se também que as críticas apontadas sejam percebidas como contribuições para o exercício da profissão.

A problematização acerca do fazer do profissional da enfermagem, possibilitada neste estudo, demonstrou a importância da inclusão dessa temática na pauta de discussão sobre o comprometimento, podendo despertar o aprofundamento de estudos que contribuam para tais discussões. 


\section{Referências}

1. Provis C, Stack S. Caring work, personal obligation and collective responsibility [Internet]. [citado 2007 Ago 13]. Disponível em: http:// nej.sagepub.com/cgi/content/abstract/11/1/5.

2. Beauchamp TL, Childress JF. Princípios de ética biomédica. São Paulo: Ediçôes Loyola; 2002.

3. Silveira RS. A construção moral do trabalhador de saúde como sujeito autônomo e ético [tese]. Florianópolis: Universidade Federal de Santa Catarina; 2006.

4. Lima EB. Motivação dos profissionais de enfermagem do Hospital Regional de Mato Grosso do Sul [Internet]. [citado 2008 Jun 22]. Disponível em: http://www.dea.ufms.br/Jornada/2001/18.

5. Freitas GF, Oguisso T. Ocorrências éticas com profissionais de enfermagem: um estudo quantitativo. Rev Esc Enferm USP. 2008;42(1). 6. Vietta EP, Uehara M, Netto KA. Evolução da enfermagem no contexto do hospital-escola: depoimentos de enfermeiros representantes da década de 70. Rev Latinoam Enferm. 1996:4(3):135-54.

7. Aguiar AB, Costa RS, Weirich CF, Bezerra AL. Gerência dos serviços de enfermagem: um estudo bibliográfico. Rev Eletrônica Enferm. 2005:7(3).
8. Ferreira LC. Organização e relações de trabalho. O trabalho em saúde e enfermagem. Texto \& Contexto Enferm. 2003;12(4):461-9.

9. Polit DF, Beck CT, Hungler BP. Fundamentos de pesquisa em enfermagem. $5^{\text {a }}$ ed. Porto Alegre: Artmed; 2004.

10. Minayo MC. Pesquisa social - teoria, método e criatividade. $2^{\mathrm{a}}$ ed. Petrópolis: Vozes; 1994.

11. Selli L. Bioética na enfermagem. São Leopoldo: Unisinos; 1998.

12. Corley MC, Minick P, Elswick RK, Jacob M. Nurse moral distress and ethical work environment. Nurs Ethics. 2005.

13. Mariotti H. Organizações de aprendizagem. Educação continuada e a empresa do futuro. São Paulo: Atlas; 1996.

14. Silveira RS. A expressão do caminhar construído junto à equipe de enfermagem de uma unidade cirúrgica sobre o cotidiano do trabalho, com vistas a uma consciência crítica [dissertação]. Florianópolis: Universidade Federal de Santa Catarina; 2000.

15. Silveira RS, Vargas MA, Lunardi VL, Martins CR, Ramos FRS. A dimensão ética do trabalho da enfermagem. A bioética e os modos de ser da enfermagem. Livro-Tema 66. Semana Brasileira de Enfermagem. Brasília: Associação Brasileira de Enfermagem; 2005. p. 39-46. 